\title{
Study of Vitamin D Status in Pregnant Women in North of Iran
}

\author{
Fariba Mirbolouk $^{1}$, Sedigheh Pakseresht ${ }^{2 *}$, Maryam Asgharnia ${ }^{1}$, Behnaz M Farjadmand ${ }^{1}$, \\ Ehsan Kazemnezhad ${ }^{3}$
}

\begin{abstract}
Objectives: The aim of this study was to check the vitamin D level in pregnant women in north of Iran (Rasht city) from spring 2013 till summer 2014.

Materials and Methods: In a retrospective cross-sectional study, all pregnant women with any gestational age without receiving vitamin D supplement before 3 months of pregnancy from two private offices of gynecologists in Rasht were studied from spring 2013 till summer 2014. All data were collected, recorded and blood sampling was done to measure serum $25(\mathrm{OH})$ vitamins D. Vitamin D deficiency and insufficiency was defined as levels of $25(\mathrm{OH}) \mathrm{D}<20$ and $<30 \mathrm{ng} / \mathrm{mL}$ for pregnant women, respectively. All data were analyzed by descriptive and analysis tests.

Results: The mean age of pregnant women was $27.5 \pm 4.6$. Mean serum $25(\mathrm{OH}) \mathrm{D}$ of pregnant women was $15.6 \pm 9.8 \mathrm{mg} / \mathrm{dL}$; vitamin D deficiency and insufficiency was observed in $69.3 \%$ (124 subjects) and 20.7\% (37 subjects) of cases, respectively. Also, there was a positive correlation between the vitamin D levels and vitamin D consumption as a supplementary one before pregnancy $(\mathrm{r}=2.473$, $P=0.001)$

Conclusion: Vitamin D deficiency in pregnant women is higher in this area (Guilan province). Vitamin D supplementation can help to increase $25(\mathrm{OH})$ D levels. However, women should ideally start vitamin D supplementation a few months before getting pregnant. Keywords: Deficiency, Pregnant, Vitamin D, Women
\end{abstract}

\section{Introduction}

Vitamin D is one of the most important and necessary vitamins for body. It has physiological role in metabolism and structure of body $(1,2)$. It plays an important role in regulating cell proliferation and differentiation, muscle function, heart, metabolism system and adaptive immune responses $(3,4)$. The vitamin D metabolic procedure involves multiple enzymatic reactions. The most important role of vitamin $\mathrm{D}$ is in metabolism process through the liver to form 25(OH)D. 25(OH)D is metabolized in the kidneys by 25 -hydroxy vitamin D-1 alpha hydroxylase (CY$\mathrm{P} 27 \mathrm{~B} 1)$ and changed into its active form, 1,25- $(\mathrm{OH})_{2} \mathrm{D}(5)$. In addition,vitamin $\mathrm{D}$ during pregnancy not only has important physiological role in metabolism and structure of body but also affects the bones, teeth and growing fetal brain (6). Moreover, it modulates human reproductive processes (7). The function of vitamin D during pregnancy for both mother and fetus remains largely undefined $(8,9)$.

Nutrition during pregnancy is the most important and controllable factor which can protect women against the induction and progress of different diseases. Studies show that foliate, folic acid, calcium, vitamin D, iron and other supplements are important during pregnancy. Sufficient levels of vitamin D in mother's body during pregnancy can decrease diabetes type I, asthma, bone problems, systematic auto immune diseases and other maternal and fetal morbidities (10-15).

Additionally, the impact of less severe vitamin D deficiency and insufficiency has received much interest in recent years $(16,17)$. There is evidence of early interest in relationship between vitamin D status and prenatal health outcomes (18). Maternal vitamin D status influences bone health in the baby (19). Studies have demonstrated associations between low levels of serum 25(OH)-vitamin $\mathrm{D}$ during pregnancy and maternal and fetal health outcomes (20).

Vitamin D can prevent transfer of infection which is as an important factor in outcome of pregnancy as an early delivery. Vitamin D, acts as a key influencing factor during pregnancy. Study showed 25(OH)-vitamin D can suppress a broad range of cytokines and inhibit inflammatory process in placenta (21). Also studies showed a positive association between in deficiency of vitamin $\mathrm{D}$ with increasing preeclampsia $(22,23)$ and diabetes $(12,24)$. Studies in Iran reported that vitamin $\mathrm{D}$ deficiency in pregnant women is $60 \%-86 \%(20-25)$. Vitamin D deficiency is common in whole world but there is difference in different countries. 
Sources of vitamin $\mathrm{D}$ depends on different factors in different areas, for example; exposure of skin to sun (VU), geographical area, color of skin, using protective sun cream, etc $(26,27)$. Based on the importance of vitamin $\mathrm{D}$ in pregnant women, health of mother and fetuses are different in geographical areas (28). The lack of particular studies in this subject, the present study was done with the purpose of determination of vitamin $\mathrm{D}$ level in serum of pregnant women in Rasht, Iran.

\section{Materials and Methods}

In this cross-sectional study, all pregnant women who received prenatal care services, in any gestational age who were taking vitamin D supplements before three months of pregnancy only (with a maximum dose of 400 units) They were selected from two private Obstetricians and Gynecologists offices in Rasht (spring 2013 till summer 2014). In this study women who had received vitamin D within three months prior to admission as a therapeutic doses were excluded. Gestational age was recorded by ultrasonography.

Data like; pregnancy, age, age at pregnancy, season, using vitamin D (up to $400 \mathrm{IU}$ ) three month before and during the pregnancy period was recorded. They were referred to a laboratory located in Rasht city to determine the vitamin D level. This was done by the Bioactivita kit (Germany). All data were collected, recorded and blood sampling was done to measure serum $25(\mathrm{OH})$ vitamins $\mathrm{D}$. Vitamin D in normal, insufficiency and deficiency levels was defined as levels of $>30,20-30(\mathrm{OH}) \mathrm{D}<20 \mathrm{ng} / \mathrm{mL}$ for pregnant women, respectively. All women participated with consent.

\section{Statistical Analysis}

Data were processed in SPSS version 21 software. Kolmogorov-Smirnov test was used to determine the normal distribution of vitamin $\mathrm{D}$ in samples which did not show any normal level distribution $(P<0.002)$. So in order to compare vitamin $\mathrm{D}$ level in different groups' nonparametric statistical test was used. Also Mann-Whitney test was used to compare two quality variables and Kruskal-Wallis test was used to compare the multiple variables and Spearman Rho test for qualitative variables. Multiple linear regression analysis was used for predicting factors in vitamin $\mathrm{D}$ level in different group. All statistical tests were performed at a significance level of $5 \%(P<0.05)$.

\section{Results}

In this study 179 (out of 186) pregnant women were analyzed. Only seven women because of having vitamin D as a treatment during 3 months before pregnancy were excluded. The mean age of women was $27.5 \pm 4.6$ (range 1943 ) years. The mean of gestational age was $8.3 \pm 2.9$ (range 5-26) weeks. Also the mean number of pregnancy was $1.3 \pm 0.6$. Results showed only $6.1 \%$ before pregnancy and $5.6 \%$ during pregnancy used supplementary vitamin D up to 400 UI. Regarding the season, women had referred as follows: $27.9 \%$ in spring, $32.4 \%$ in summer $13.4 \%$ in fall and $26.3 \%$ in winter.

The mean level of vitamin $\mathrm{D}$ in pregnant women was $15.6 \pm 9.8 \mathrm{ng} / \mathrm{mL}$, median 12.5 and with confidence interval $95 \% 14.1-17$ (range $4-50$ ). Based on this study $69.27 \%$ deficiency, $20.67 \%$ insufficiency and only $10.06 \%$ had normal (sufficiency) vitamin D level (Figure 1).

There was not significant association between levels of vitamin $\mathrm{D}$ with mother's age $(\mathrm{r}=0.139, P=0.064)$ and gestational age $(r=0.095, P=0.207)$ by Spearman correlation test. The mean levels of vitamin $\mathrm{D}$ between two groups of women with and without having supplementary vitamin $\mathrm{D}$ during pregnancy were significantly different $(P<0.0001)$. It also showed significant difference in women who used or did not use vitamin $D$ before pregnancy $(P<0.0001$; Table 1$)$.

There was no statistical significant difference between vitamin D levels of women with maternal age $(P=0.298)$, gestational age $(P=0.607)$ and number of pregnancy $(P=0.592)$ by Spearman test (Table 2$)$.

There was no statistical significance among the seasons, but results showed the highest (75\%) deficiency of vitamin $\mathrm{D}$ level in women in autumn (Table 3).

Multiple linear regression analyzing showed that only using vitamin $\mathrm{D}$ before pregnancy was a predictor factor in vitamin $\mathrm{D}$ level $(P<0.0001)$. All of the related variables with vitamin $\mathrm{D}$ such as age, pregnancy, age at pregnancy, vitamin $\mathrm{D}$ use before and during the pregnancy were in-

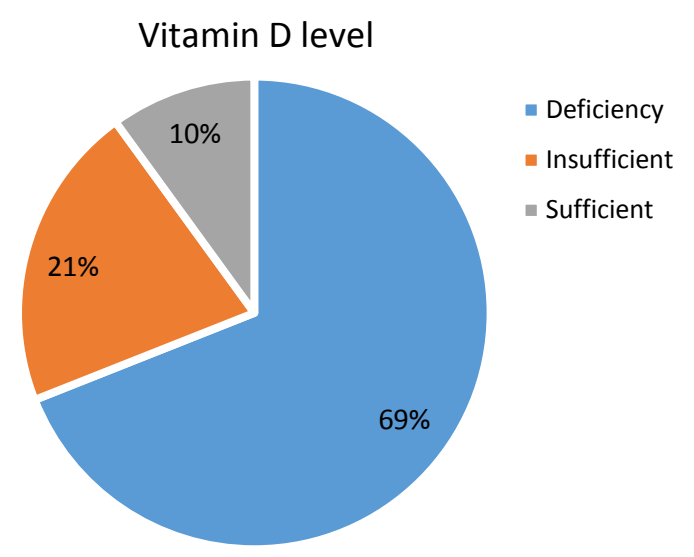

Figure 1. Vitamin D Level in the Studied Pregnant Women.

Table 1. Comparing Mean Level of Vitamin D When Using Supplementary Vitamin D

\begin{tabular}{lccc}
\hline Variables & No. (\%) & $\begin{array}{r}\text { Vitamin D, } \\
\text { Mean } \pm \text { SD }\end{array}$ & $\boldsymbol{P}$ \\
\hline $\begin{array}{l}\text { Using vitamin D during } \\
\text { pregnancy }\end{array}$ & & & 0.0001 \\
$\quad$ Yes & $10(5.6)$ & $35.4 \pm 6.6$ & \\
$\quad$ No & $169(94.4)$ & $14.3 \pm 8.5$ & \\
$\begin{array}{l}\text { Using vitamin D before } \\
\text { pregnancy }\end{array}$ & & & 0.0001 \\
$\quad$ Yes & $11(6.1)$ & $35.4 \pm 6.3$ & \\
No & $168(93.9)$ & $14.23 \pm 8.4$ & \\
\hline
\end{tabular}


Table 2. The mean Quantity Variables Based on the Vitamin D Level in Women

\begin{tabular}{|c|c|c|c|c|}
\hline \multirow{2}{*}{ Variables } & \multicolumn{4}{|c|}{ Vitamin D Status } \\
\hline & Sufficiency (Mean \pm SD) & Indeficiency (Mean \pm SD) & Deficiency (Mean \pm SD) & $P$ \\
\hline Age of mother & $28.78 \pm 4.42$ & $27.97 \pm 3.91$ & $27.17 \pm 4.78$ & 0.298 \\
\hline Gestational age & $7.72 \pm 2.78$ & $8.55 \pm 2.91$ & $8.36 \pm 2.97$ & 0.607 \\
\hline Number of pregnancies & $1.39 \pm 0.502$ & $1.22 \pm 0.479$ & $1.27 \pm 0.626$ & 0.592 \\
\hline
\end{tabular}

Table 3. Vitamin D Level in Pregnant Women Based on the Season

\begin{tabular}{lcccc}
\hline \multirow{2}{*}{ Season } & \multicolumn{4}{c}{ Vitamin D Status } \\
\cline { 2 - 5 } & Mean \pm SD & Sufficiency & Insufficiency & Deficiency \\
\hline Spring & $5.1 \pm 2.17$ & $6(12)$ & $10(20)$ & $34(68)$ \\
Summer & $4.9 \pm 1.15$ & $5(8.6)$ & $14(24.1)$ & $39(67.2)$ \\
Autumn & $10 \pm 1.14$ & $3(12.5)$ & $3(12.5)$ & $18(75)$ \\
Winter & $6.9 \pm 3.15$ & $4(8.5)$ & $10(21.3)$ & $33(70.2)$ \\
$P$ value & 0.578 & & 0.932 & \\
\hline
\end{tabular}

Table 4. The Regression Coefficient of Predictors of Vitamin D Level by Multiple Linear Regression Models

\begin{tabular}{|c|c|c|c|c|c|}
\hline \multirow{2}{*}{ Predictive Variables } & \multirow{2}{*}{$\beta$} & \multirow{2}{*}{ SE } & \multirow{2}{*}{$P$} & \multicolumn{2}{|l|}{$\mathrm{Cl}(95 \%)$} \\
\hline & & & & Lower & Upper \\
\hline Constant & 56.66 & 4.821 & 0.0001 & 47.153 & 66.181 \\
\hline $\begin{array}{l}\text { Lack of vitamin D } \\
\text { supplementation before } \\
\text { pregnancy }\end{array}$ & -21.25 & 2.473 & 0.0001 & -26.131 & -16.369 \\
\hline
\end{tabular}

putted in step by step on the multi linear regression model (Table 4). The result showed the mean (mean + SE ) of vitamin $\mathrm{D}$ level in women, who used vitamin $\mathrm{D}$ before pregnancy was higher $(21.25+2.47 \mathrm{ng} / \mathrm{mL})$ than those who did not receive vitamin D supplementation.

\section{Discussion}

According to findings in this study $69.27 \%$ of pregnant women had vitamin D deficiency and $20.67 \%$ experienced insufficient levels of vitamin $\mathrm{D}$; mean level of vitamin D in pregnant women was $15.6 \pm 9.8 \mathrm{ng} / \mathrm{mL}$. Karim et al reported $46 \%$ deficient, $32 \%$ insufficient and $23 \%$ sufficient (normal) vitamin levels in women (29). Also Ergür et al found vitamin D deficiency in about $81.3 \%$ of women (30). Studies in other areas reported that the level of vitamin $\mathrm{D}<10 \mathrm{ng} / \mathrm{mL}$ is different, such as; $17 \%-18 \%$ in Caucasian pregnant women (30-32), $42 \%$ in New Zealand pregnant women $(33), 32 \%-42 \%$ in Indian pregnant women (34), 59\%-84\% in Holland pregnant women who were non-European immigrants (35) and 48\% in pregnant women from Kuwait (36). Rodriguez et al reported that pregnant women had $31.8 \%$ insufficiency and $19.7 \%$ deficiency in vitamin D level (37). Mir et al reported about two-thirds of pregnant Kashmiri women were vitamin D insufficient or deficient and pregnant women from south and north India have high vitamin D deficiency levels ranging 67\%-96\% (27).

The present study showed that there was no statistical sig- nificance between vitamin $\mathrm{D}$ level during different seasons (vitamin D level was lower in summer than autumn), ( $\mathrm{P}>$ 0.05). Kazemi et al observed that deficiency of vitamin $D$ in pregnant women in summer was lower than in winter (28). Similarly, Marwaha et al reported that seasonal differences during the three trimesters $25(\mathrm{OH}) \mathrm{D}$ levels were observed as significantly lower in winter in the second and third trimesters in pregnancy (38), while Rodriguez et al reported significant seasonal differences with vitamin $\mathrm{D}$ level (37). Kazemi et al reported the mean level of vitamin $\mathrm{D}$ was $19.4 \pm 3.9 \mathrm{ng} / \mathrm{mL}$ and deficiency of vitamin $\mathrm{D}$ in women was $86 \%$ in winter and $46 \%$ in summer (28). The study by Sahu et al showed a significant effect of season on vitamin D deficiency, recording $54 \%$ in the period from May to October and 93\% from November to April (34). Considering Guilan's (province) climatic characteristics throughout the year, as being mostly cloudy (cloudier in the autumn and winter compared to spring and summer), it could be claimed that on average, 169 days of the year it is completely cloudy and women in this area are not exposed to much sunshine. On the other hand, pregnant women's conditions are particularly important. Given that women in Iran have to cover most parts of their body and are limited in being exposed to sunlight because of cultural issue, vitamin D deficiency is higher in this area. Of course, base line values of vitamin $\mathrm{D}$ and calcium levels during the pregnancy in some women can be important factors affecting the prevalence of vitamin D deficiency. Future researches with larger sample size may clarify and reveal more exact results.

Present study did not find significant statistical differences between vitamin $\mathrm{D}$ and age of women, gestational age and number of pregnancy. Marwaha et al did not show significant statistical differences between vitamin $\mathrm{D}$ and gestational age, too (38). Rodriguez et al found significant statistical differences between gestational age and the concentration of vitamin D. Also he showed similar results between vitamin $\mathrm{D}$ levels and the number of pregnancies (31). This difference may be due to different sample size and population.

The result revealed that only the women who had used vitamin $\mathrm{D}$ before pregnancy had the mean of vitamin $\mathrm{D}$ level higher $(21.25+2.47 \mathrm{ng} / \mathrm{mL})$ compared to those who experienced the lack of vitamin D. Vitamin D supplementation with $2000 \mathrm{IU} /$ day or $60000 \mathrm{IU} /$ month is very effective and safe in pregnant women (27). Meanwhile, some studies reported that using vitamin D during the pregnancy period significantly increased the level of vitamin D (27,39-41). 


\section{Conclusion}

Finally, as result of this study, majority of women had deficiency and insufficiency of vitamin $\mathrm{D}$. It may be due to residency in north of Iran (Caspian Sea area) which is cloudy most of the year. Regardless of this factor (being exposed to sunshine), women's deficiency of vitamin D level has been observed in Iran, that can be as a result of especial women clothing in Iran. All these could be source of deficiency of vitamin D level in women. So, 25-hydroxy vitamin $\mathrm{D}$ test is recommended during pregnancy.

Among the limitations of this study we can refer to the fact that some women had not used vitamin D regularly before and during the pregnancy and there was not any baseline of vitamin level before pregnancy.

\section{Ethical Issues}

This study was financially supported by Guilan University of Medical Science, Rasht, Iran with IR.GUMS. REC.2015.838 reference number and approved by the ethical committee.

\section{Conflict of Interests}

The authors have not any conflict of interests.

\section{Finnacial Support}

This study was financially supported by Guilan University of Medical Science, Rasht, Iran.

\section{Acknowledgments}

We would like to thank all who assisted us in this study.

\section{References}

1. Christakos S, Ajibade DV, Dhawan P, Fechner AJ, Mady LJ. Vitamin D: metabolism. Rheum Dis Clin North Am. 2012;38(1):1-11. doi: 0.1016/j. rdc.2012.03.003.

2. Maddah M, Sharami SH, Neyestani TR. Vitamin D insufficiency among postmenopausal women in urban and rural areas in Guilan, Northern Iran. J Nutr Elder. 2009;28(4):386-93. doi: 10.1080/01639360903393523.

3. Bikle DD. Vitamin D regulation of immune function. Vitam Horm. 2011;86:1-21. doi: 10.1016/B978-0-12386960-9.00001-0.

4. Lagishetty V, Liu NQ, Hewison M. Vitamin D metabolism and innate immunity. Mol Cell Endocrinol. 2011;347(1-2):97-105. doi: 10.1016/j. mce.2011.04.015.

5. Christakos S, Dhawan P, Benn B, et al. Vitamin D: molecular mechanism of action. Ann N Y Acad f Sci. 2007;1116:340-8.

6. Hollis BW. Vitamin D requirement during pregnancy and lactation. J Bone Min Res. 2007;22(S2):V39-V44. doi: 10.1359/jbmr.07s215.

7. Hou W, Yan XT, Bai CM, Zhang XW, Hui LY, Yu XW. Decreased serum vitamin D levels in early spontaneous pregnancy loss. Eur J Clin Nutr. 2016 May 25. doi: 10.1038/ejcn.2016.83.

8. Bouillon R. Vitamin D: from photosynthesis, metabolism, and action to clinical applications. In: De Groot LJ, Jameson JL, eds. Endocrinology. Philadelphia: WB Saunders; 2001:1009-28.

9. Hollis BW, Wagner CL. The role of the parent compound vitamin $\mathrm{D}$ with respect to metabolism and function: why clinical dose intervals can affect clinical outcomes. J Clin Endocrinol Metab. 2013;98(12):4619-28. doi: 10.1210/jc.2013-653.

10. Lange NE, Litonjua A, Hawrylowicz CM, Weiss S. Vitamin D. The immune system and asthma. Expert Rev Clin Immunol. 2009;5(6):693-702.

11. Gale CR, Robinson SM, Harvey NC, et al. Maternal vitamin $\mathrm{D}$ status during pregnancy and child outcomes. Eur J Clinical Nutr. 2008;62(1):68-77.

12. Ozfirat Z, Chowdhury TA. Vitamin D deficiency and type 2 diabetes. Postgrad Med J. 2010;86(1011):18-25. doi: 10.1136/pgmj.2009.078626.

13. Takiishi T, Gysemans C, Bouillon R, Mathieu C. Vitamin D and diabetes. Endocrinol Metab Clin North Am. 2010;39(2):419-46.doi: 10.1016/j. ecl.2010.02.013.

14. Eyles D, Feron F, Cui X, et al. Developmental vitamin $\mathrm{D}$ deficiency causes abnormal brain development. Psychoneuroendocrinology. 2009;34:S247-S57. doi: 10.1016/j.psyneuen.2009.04.015.

15. Holmøy T, Moen S. Assessing vitamin D in the central nervous system. Acta Neurol Scand Suppl. 2010;122(190):88-92. doi: 10.1111/j.6000404.2010.01383.x.

16. Moon RJ, Harvey NC, Davies JH, Cooper C. Vitamin $\mathrm{D}$ and skeletal health in infancy and childhood. Osteoporosis Int. 2014;25(12):2673-84. doi: 10.1007/ s00198-014-2783-5.

17. Hollis BW, Johnson D, Hulsey TC, Ebeling M, Wagner CL. Vitamin D supplementation during pregnancy: Double-blind, randomized clinical trial of safety and effectiveness. J Bone Miner Res. 2011;26(10):2341-57. doi: 10.1002/jbmr.463.

18. Thorne-Lyman A, Fawzi WW Vitamin D during pregnancy and maternal, neonatal and infant health outcomes: a systematic review and meta-analysi. Paediatr Perinat Epidemiol. 2012;26:75-90. doi: 10.1111/j.365-3016.2012.01283.x.

19. Ponsonby AL, Lucas RM, Lewis S, Halliday J. Vitamin D status during pregnancy and aspects of offspring health. Nutrients. 2010;2(3):389-407. doi: 10.3390/ nu2030389.

20. Harvey NC, Holroyd C, Ntani G, et al. Vitamin D supplementation in pregnancy: a systematic review. Health Technol Assess. 2014;18(45):1. doi: 10.3310/ hta18450.

21. Liu N, Kaplan A, Low J, et al. Vitamin D induces innate antibacterial responses in human trophoblasts via an intracrine pathway. Biol Reprod. 2009;80(3):398-406. doi: 10.1095/biolreprod.108.073577.

22. Baker AM, HaeriS, Camargo CA Jr, Espinola JA, Stuebe AM. A nested case-control study of midgestation vitamin D deficiency and risk of severe preeclampsia. 
J Clin Endocrinol Metab 2010;95(11):5105-9. doi: 10.1210/jc.2010-0996.

23. Bodnar LM, Catov JM, Simhan HN, Holick MF, Powers RW, Roberts JM. Maternal vitamin D deficiency increases the risk of preeclampsia. J Clin Endocrinol Metab. 2007;92(9):3517-22.

24. Pittas AG, Sun Q, Manson JE, Dawson-Hughes B, Hu FB. Plasma 25-hydroxyvitamin D concentration and risk of incident type 2 diabetes in women. Diabetes Care. 2010;33(9):2021-3. doi: 10.337/dc10-0790.

25. Kovacs CS. Vitamin D in pregnancy and lactation: maternal, fetal, and neonatal outcomes from human and animal studies. Am J Clin Nutr. 2008;88(2):520S$8 \mathrm{~S}$.

26. Zargar AH, Ahmad S, Masoodi SR, et al. Vitamin D status in apparently healthy adults in Kashmir Valley of Indian subcontinent. Postgrad Med J. 2007;83(985):713-6.

27. Mir SA, Masoodi SR, Shafi S, et al. Efficacy and safety of vitamin $\mathrm{D}$ supplementation during pregnancy: a randomized trial of two different levels of dosing on maternal and neonatal Vitamin D outcome. Indian J Endocrinol Metab. 2016;20(3):337-42. doi: 10.4103/2230-8210.179991.

28. Kazemi A, Sharifi F, Jafari N, Mousavinasab N. High prevalence of vitamin $\mathrm{D}$ deficiency among pregnant women and their newborns in an Iranian population. J Womens Health. 2009;18(6):835-9. doi: 10.1089/ jwh.2008.0954.

29. Karim SA, Nusrat U, Aziz S. Vitamin D deficiency in pregnant women and their newborns as seen at a tertiary-care center in Karachi, Pakistan. Int J Gynecol Obstet. 2011;112(1):59-62. doi: 10.1016/j. ijgo.2010.07.034.

30. Ergür AT, Berberoğlu M, Atasay B, et al. Vitamin D deficiency in Turkish mothers and their neonates and in women of reproductive age. J Clin Res Pediatr Endocrinol. 2009;1(6):266-9. doi: 10.4274/jcrpe. v1i6.266.

31. Javaid M, Crozier S, Harvey N, et al. Maternal vitamin $\mathrm{D}$ status during pregnancy and childhood bone mass at age 9 years: a longitudinal study. Lancet. 2006;367(9504):36-43.

32. Holmes VA, Barnes MS, Alexander HD, McFaul P, Wallace JM. Vitamin D deficiency and insufficiency in pregnant women: a longitudinal study. Br J Nutr. 2009;102(06):876-81. doi: 10.1017/ S0007114509297236.

33. Ekeroma AJ, Camargo CA Jr, Scragg R, et al. Predictors of vitamin D status in pregnant women in New Zealand. N Z Med J. 2015;128(1422):24-34.

34. Sahu M, Bhatia V, Aggarwal A, et al. Vitamin D deficiency in rural girls and pregnant women despite abundant sunshine in northern India. Clin Endocrinol. 2009;70(5):680-4. doi: 10.1111/j.13652265.2008.03360.x.

35. van der Meer IM, Karamali NS, Boeke AJP, et al. High prevalence of vitamin $\mathrm{D}$ deficiency in pregnant nonWestern women in the Hague, Netherlands. Am J Clin Nutr. 2006;84(2):350-3.

36. Molla AM, Al Badawi M, Hammoud MS, et al. Vitamin D status of mothers and their neonates in Kuwait. Pediatr Int. 2005;47(6):649-52.

37. Rodriguez A, García-Esteban R, Basterretxea M, et al. Associations of maternal circulating 25hydroxyvitamin D3 concentration with pregnancy and birth outcomes. BJOG. 2015;122(12):1695-704. doi: 10.1111/1471-0528.13074.

38. Marwaha R, Tandon N, Chopra S, Agarwal N, Garg M, Sharma B, et al. Vitamin D status in pregnant Indian women across trimesters and different seasons and its correlation with neonatal serum 25-hydroxyvitamin D levels. Br J Nutr. 2011;106(09):1383-9. doi: 10.017/ S000711451100170X.

39. Bodnar LM, Simhan HN, Powers RW, Frank MP, Cooperstein E, Roberts JM. High prevalence of vitamin D insufficiency in black and white pregnant women residing in the northern United States and their neonates. J Nutr. 2007;137(2):447-52.

40. Shakiba M, Iranmanesh MR. Vitamin D requirement in pregnancy to prevent deficiency in neonates: a randomised trial. Singapore Med J. 2013;54(5):285-8.

41. Hashemipour S, Lalooha F, Zahir Mirdamadi S, Ziaee A, Dabaghi Ghaleh T. Effect of vitamin D administration in vitamin D-deficient pregnant women on maternal and neonatal serum calcium and vitamin D concentrations: a randomised clinical trial. Br J Nutr. 2013;110(09):1611-6. doi: 10.017/ S0007114513001244.

Copyright (c) 2016 The Author(s); This is an open-access article distributed under the terms of the Creative Commons Attribution License (http://creativecommons.org/licenses/by/4.0), which permits unrestricted use, distribution, and reproduction in any medium, provided the original work is properly cited. 